\title{
AS PRÁTICAS EM COMUNÁUTICA NO CENTRO DA APRENDIZAGEM ONLINE
}

\author{
SERAPHIN AlAVA*
}

RESUMO: A implementação de novas práticas coletivas e de comunidades virtuais nos espaços da modernidade avançada questiona as abordagens sociológicas, comunicacionais, educativas e econômicas. Sabe-se atualmente que a colaboração na aprendizagem online é um fator suplementar de sucesso e de enriquecimento da formação e que existem ferramentas para implementá-la, mas podemos nos questionar quanto à parte real atribuída pelos alunos às práticas comunáuticas nas respectivas aprendizagens, e mais especificamente no ensino online. Com base numa investigação realizada em 2009 junto ao público adulto referenciado, tanto no que diz respeito às formações a distância como às formações online, descreveremos as práticas comunáuticas e exporemos como e com que competências ativas se estruturam estas práticas digitais de interação e de cooperação pedagógica.

Palavras-chave: Práticas coletivas. Coaprendizagem. Práticas comunáuticas. Formação aberta e a distância. Pedagogia digital.

\section{The PRACTICES OF "COMMUNAUtique" IN THE ONLINE LEARNING CORE}

\begin{abstract}
Several sociological, educative and economics approaches are questioned by this deployment of new collective practices and virtual communities in advanced modernity spaces. The concepts of groupware and collective intelligence are the proof of existence of a new determining social movement. However, it is important to ask ourselves what actual part is given to groupware practices by the learners in their learning approach and more specifically in e-learning. Based on a 2009 research lead with adults following either remote trainings or e-training, we describe here the groupware practices and we expose the methods and the active skills used to structure theses digital practices of interaction and pedagogical cooperation. We try to describe these practices and to understand what would promote the development of these skills specific to collectives' practices.
\end{abstract}

Key words: Collective practices. Cooperative learning. Groupware practices. Open and remote training. Digital pedagogy.

Professor de Educação e Ciência da Educação da Universidade de Toulouse II (França). E-mail: seraphin.alava@gmail.com 


\section{LES PRATIQUES EN COMMUNAUTIQUE AU CEUR DES APPRENTISSAGES EN LIGNE}

RÉSUMÉ: L'émergence d'un phénomène collectif ou communautaire est un des points déterminants des spécificités du Cyberespace depuis plus de dix ans. On sait que la collaboration dans l'apprentissage en ligne est un facteur supplémentaire de réussite et d'enrichissement de la formation. Mais nous pouvons nous demander quelle est la part réelle qui est donnée par les apprenants aux pratiques communautiques dans leurs apprentissages. En nous appuyant sur une recherche conduite en 2009 auprès d'un public adulte référencé, qu'il s'agisse de formations à distance ou de formations en ligne, nous décrirons les pratiques communautiques et nous exposerons comment et avec quelles compétences actives se structurent ces pratiques numériques d'interaction et de coopération pédagogique. Nous chercherons à décrire ces pratiques et à comprendre ce qui favoriserait le développement de ces compétences spécifiques à la pratique collective.

Mots-clés: Pratiques collectives. Co-apprentissage. Pratiques communautiques. Formation ouverte et à distance. Intelligence collective. Cyberespace. Pédagogie numérique.

\section{Introdução}

A emergência de um fenômeno coletivo ou comunitário é um dos pontos determinantes das especificidades do ciberespaço nos últimos anos. Este movimento situa-se na necessidade comprovada de o sujeito social encontrar espaços seculares de sociabilidade que a sociedade industrial lhe fez perder (Rheingold, 1993). Esta implementação de novas práticas coletivas e de comunidades virtuais nos espaços da modernidade avançada questiona as abordagens sociológicas, comunicacionais, educativas e econômicas.

A própria existência de um campo de práticas coletivas ou comunitárias é afirmada e já teorizada pelas abordagens de Charlier (2006), Slevin (2000), Mehra (2004), Morino (1994) e Schuler (1996), que insistem nas relações da internet e na emergência de novas formas de associações humanas. Os trabalhos de Wellman (1999), de Sarr (2002) e de Harvey (1995) demonstraram que as comunidades virtuais são verdadeiras comunidades, não obstante o respectivo aspecto de espaço imaterial e intangível. No seio destas comunidades, desenvolvem-se práticas coletivas comunitárias e modalidades de ações sociais, colocando o grupo ou o coletivo no centro da ação. Há alguns anos, as ferramentas técnicas e os artefatos digitais favoreceram as trocas entre os indivíduos, os grupos e as comunidades. A Web 2.0 acelerou as práticas, favorecendo a emergência das redes sociais, dos espaços Wiki e dos blogs. Estas novas potencialidades transformaram consideravelmente a internet, que é considerada atualmente um "ciberespaço de práticas digitais". Contudo, a emergência e o desenvolvimento de formas híbridas de trabalho, de comunicação e de aprendizagem questionam-nos, de 
forma prospectiva, sobre a noção de "ação coletiva" e sobre a emergência de novas formas de práticas humanas de trabalho e de cognição no seio do ciberespaço.

Sinônimo de rede, web, net, a designação "ciberespaço" reflete uma nova concepção de rede, gerando práticas sociais que chegam a um público cada vez mais vasto. O ciberespaço é um local virtual onde os indivíduos interagem de forma real, cada vez mais utilizado nos últimos dez anos. Com o nascimento das primeiras redes sociais, o ciberespaço tornou-se um verdadeiro espaço social determinante para a sociedade. Desse modo, as relações cibernéticas e humanas estão inegavelmente interligadas. A abordagem ao tempo, ao espaço e aos indivíduos é totalmente modificada. A noção de trocas, de ações cooperativas e de participação dos alunos é determinante. As redes sociais permitem compartilhar informações, como é o caso de enciclopédias como a Wikipédia, por exemplo, de websites de partilha de vídeos como o You tube e o Dailymotion, bem como de blogs que oferecem novas perspectivas a alunos e professores no que diz respeito à aprendizagem. Agora, procura-se muito mais proceder à construção conjunta de saberes entre alunos.

\section{As práticas coletivas de comunicação e de aprendizagem}

Atualmente, o desenvolvimento de práticas de interação, de troca e de cooperação na internet é um fato social importante que transforma as práticas digitais.

Os jovens adultos, por vezes designados como "digitais nativos", dispõem de práticas digitais que valorizam em grande medida esta evolução comunáutica da internet. Os conceitos de software de grupo, de software comunitário e depois de comunáutica, de ciberespaço e de comunidades de aprendizagem são sinais da existência de um movimento social determinante que nos obriga a pensar as práticas sociais num espaço digital público, caracterizado por uma comunicação e por práticas comunitárias, coletivas e interativas.

Nos anos de 1960, McLuhan (1968) elaborou uma teoria geral relativa à vida social que viria a influenciar a nossa percepção, no que diz respeito aos meios de comunicação social. Na sua obra Understanding the media, the extension of Man, o autor explica que a eletrônica é um elemento que altera a percepção que cada pessoa tem de si próprio e do mundo. A tecnologia constitui uma nova oportunidade de melhorar as possibilidades do ser humano. O computador torna-se assim um prolongamento do nosso cérebro. Para o autor, é necessário estudar o meio para melhor compreender o Homem ancorado à sociedade. Na sua teoria, o autor destaca a relevância de dois tipos de meios de comunicação social: "hot" e "cool". Os meios "hot" correspondem a fontes de informação densas, mas que concedem pouco espaço à participação do utilizador, ao passo que os meios "cool" exigem uma maior interação com o utilizador. Os 
meios "cool" favorecem a "retribalização" e, consequentemente, uma "interdependência" e um "pensamento comunitário", reduzindo a noção de individualismo inerente à sociedade contemporânea. Este autor encontrava-se "à frente de seu tempo", sendo que se pode considerar que, de algum modo, previu a ascensão do ciberespaço, uma vez que se referia ao mundo associado à eletrônica em termos de "aldeia global".

\section{Figura 1}

Esquema 2: distribuição das práticas digitais de acordo com a idade

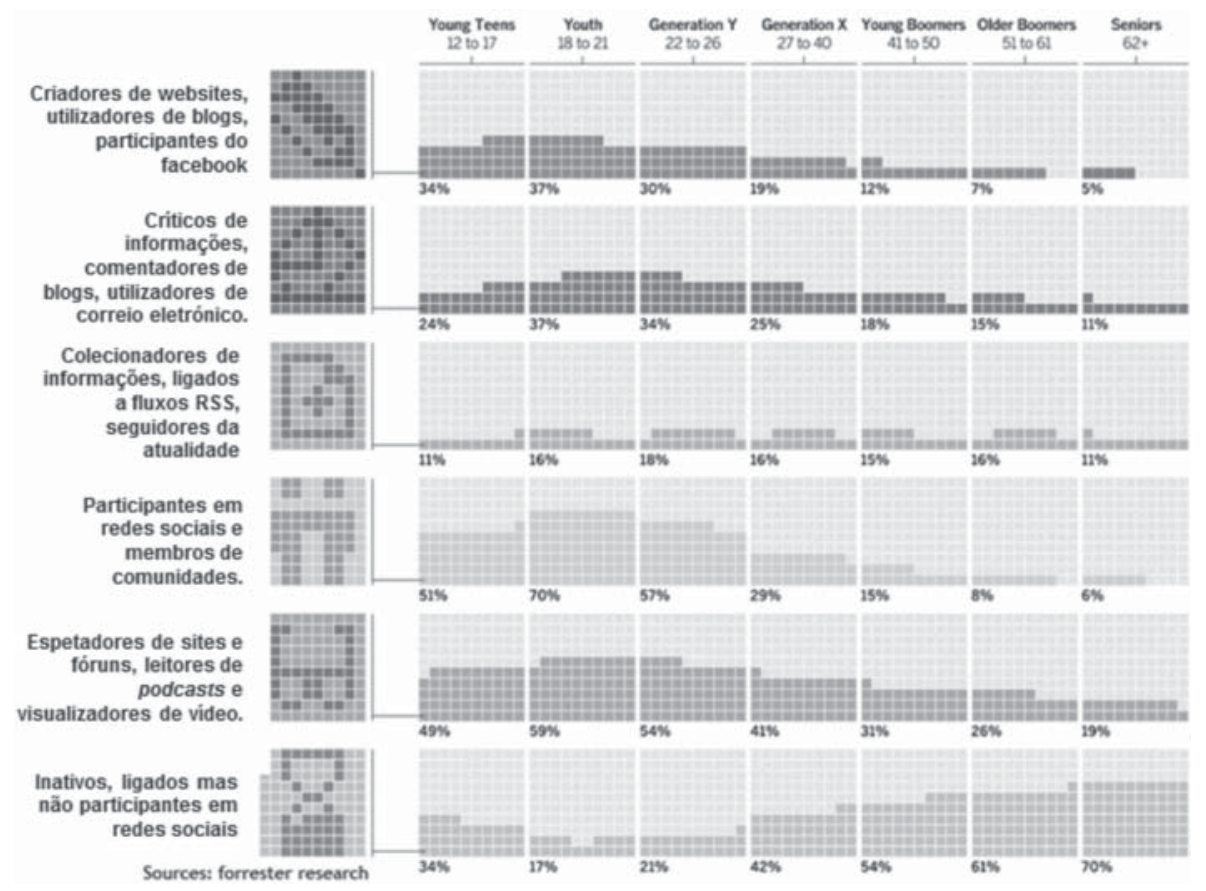

Fonte: Forrester research.

É precisamente esta noção que Levy (1997) retomará alguns anos depois, no momento em que as tecnologias de informação e comunicação (TIC) e a internet já se tinham desenvolvido consideravelmente. $\mathrm{O}$ autor considera-as ferramentas que favorecem um pensamento coletivo de toda a espécie humana. A internet representa assim o pilar da inteligência coletiva. De fato, ela reúne as vantagens de todos os meios de comunicação social (elevada divulgação associada à imprensa, rádio, televisão e reciprocidade associada à comunicação por telefone) e oferece a possibilidade de criar uma ou várias comunidades - ideia de retribalização de McLuhan. É uma nova "fonte de heterogeneidade e de diversidade" que reúne os internautas em torno de uma cibercultura comum. 
Em 1995, Harvey, retomando os trabalhos de McLuhan, propôs um conceito federativo ao utilizar o termo "comunáutica". O autor fala de um conjunto de práticas sociais coletivas e de um tipo de relação virtual sociocomunitária que existe no ciberespaço. Na obra subordinada ao tema Ciberespaço e comunáutica, Harvey (1995, p. 112) estabelece uma definição do conceito: "pode definir-se a comunáutica como um espaço público caraterizado por uma comunicação entre os grupos, ou seja, entre os membros e o respectivo grupo, entre os membros propriamente ditos e entre diferentes grupos, através de tecnologias interativas de comunicação e informação". A dimensão essencial do conceito está, neste caso, ligada à sua natureza de local interativo de comunicação social.

\section{Figura 2}

Esquema 3: as práticas comunáuticas no seio do ciberespaço atual

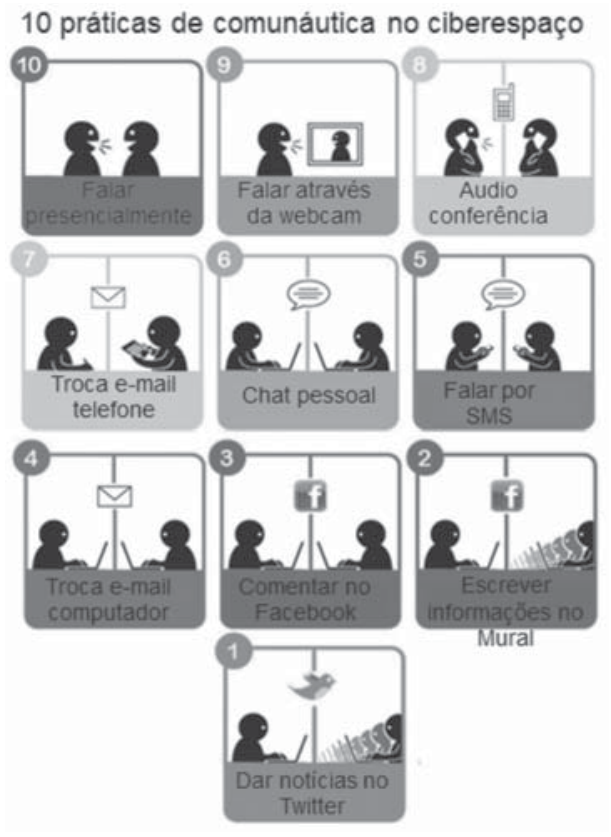

Essas práticas de comunicação que predominam no seio dos digitais nativos já não podem ser consideradas simples interações informacionais, mas contribuem para a emergência de uma nova relação social e, como veremos, cognitiva, que carateriza os espaços de comunáutica.

Harvey (op. cit.) questionou-se relativamente às consequências dessas novas práticas sobre o funcionamento social. Será que essas práticas coletivas de comunicação contribuem para uma mutação de nossas sociedades? Em que sentido? Esses 
espaços públicos virtuais a que chamamos atualmente redes sociais ou Web 2.0 modificaram as modalidades sociais, sendo que as mais conhecidas são o trabalho, o comércio, a cultura e as relações sociais.

Em 2002, Sarr prolongou esta análise diagnosticando que, nas atuais utilizações sociais da internet, a dinâmica comunitária torna-se um elemento central do processo de existência social digital. A comunáutica pode mesmo definir não só os espaços sociais virtuais caraterizados pela comunicação dos membros e dos grupos, mas também um conjunto de práticas e de utilizações sociais dos mundos virtuais ou reais que se caracterizam pela intercomunicação, a cooperação e a partilha de objetos e saberes. A comunidade virtual é, nesse sentido, um novo espaço de desenvolvimento da relação social e do ensino (Keeble \& Loader, 2002).

\section{Cognição e competências nas práticas em comunáutica}

A questão que nos interessa agora, num espaço em que a comunáutica é central, consiste em compreender adequadamente como e através de que procedimentos estas utilizações coletivas de ferramentas e de situações digitais irão perturbar, valorizar e potencializar as práticas antigas e, acima de tudo, as práticas de ensino e de aprendizagem.

As práticas em comunáutica necessitam de competências particulares? Estas práticas sociais, informacionais e cognitivas possuem uma especificidade e modalidades de execução específicas que necessitam de uma reconfiguração das competências? Por fim, os modos de cognição, os estilos e as estratégias de aprendizagem são modificados nestas configurações virtuais?

Nos anos de 1950, o antropólogo Bateson contribuiu para a elaboração do construtivismo contemporâneo. Inspirando-se na teoria da informação e da comunicação, Bateson publicou, em 1951, uma obra que apresenta a comunicação como a matriz na qual se inserem as atividades humanas. Para o autor, a aprendizagem online tem em conta as interações e, por isso, deve ser considerada sob o ponto de vista comunicacional. Por sua vez, os trabalhos de Gardner $(1993,1997)$ e de Bandura (1976) destacam a variabilidade dos comportamentos e dos modos de aprendizagem online; a noção de estilos de aprendizagem assenta na existência de perfis de inteligências pessoais e de comportamentos de pesquisa de informações e de socializações digitais específicas. Os primeiros trabalhos sobre os modos de aprendizagem digitais procuraram caraterizar os alunos através das respectivas preferências perceptuais. A maior parte das tentativas para ligar as preferências auditivas, táteis ou visuais aos resultados não demonstrou qualquer relação significativa entre estas preferências e o sucesso (Billings \& Cobb, 1992). Em seguida, as investigações procuraram comparar os estilos de aprendizagem dos alunos online com os dos alunos presenciais. 
Com o computador e a rede, a reflexão do aluno passa do cérebro para a tela. O cérebro é assim completado pela tecnicidade da máquina e da rede, que acelera o pensamento e dá acesso ao saber infinito dos outros internautas. Quando se fala de cognição, o interesse se focaliza no tratamento da informação. Este sistema pode ser individual ou compartilhado entre vários indivíduos. Com a rede, acede-se a uma "cognição social", ou seja, os internautas estão em "interação no seio de uma rede social". Bruner (1990) e Gardner (1997) superam rapidamente o modelo puramente matemático de inteligência para destacar desde logo o papel dos processos mediadores no núcleo da cognição. A motivação, a interação e a confrontação conduziram-nos a considerar a cognição como sendo social e sociocognitiva.

Num espaço comunáutico, as modalidades de ações, interações e cognições têm em conta esta dimensão coletiva e interativa. De kerckhove e Scheffel-Dunand (2002, p. 3-5) propõem que se fale de inteligência conectiva:

\begin{abstract}
O conceito de inteligência conectiva revela uma dimensão da psicologia humana até o momento ignorada ou considerada episódica ou acidental, a comunidade mental. A inteligência e a sensibilidade são, geralmente, consideradas como tendo uma natureza exclusivamente individual. Sem dúvida que acreditamos poder compartilhar sentimentos, mas apenas por empatia, não num espaço mental verdadeiramente comum. Adquirimos e conservamos durante tanto tempo o hábito de pensar por nós próprios, de nos apropriarmos dos recursos da linguagem através do pensamento e da escrita, que consideramos natural a inteligência privada e excepcionais os fenômenos de inteligência e de sensibilidade coletivos.
\end{abstract}

Assim, aprender através de um sistema de ensino online coloca em jogo competências cognitivas, sociais e afetivas novas ou recontextualizadas.

\title{
Metodologia e primeiros resultados
}

Para descrever as práticas de comunáutica e compreender os processos de valorização e de reforço das práticas digitais e pedagógicas, procedemos a uma ação clássica de coleta de dados centrada num questionário de pesquisa administrado pela internet. Em seguida, foram aplicados dois testes para verificar o estilo de aprendizagem privilegiado e o sentimento de eficácia pessoal declarado pelos sujeitos.

\section{Público}

Para descrever as práticas de comunáutica e compreender os processos de valorização e de reforço das práticas ao mesmo tempo digitais e pedagógicas, trabalhamos segundo um método clássico de coleta de dados centrada num questionário. Quisemos que este questionário fosse administrado diretamente online. Por outro lado, propusemos aos organismos de formação a difusão de um anúncio na respectiva 
plataforma de ensino a distância e/ou nos fóruns, explicando o objetivo do questionário e incitando os alunos a participar do estudo clicando no link indicado. Como sabíamos que o questionário de administração direta oferece geralmente menos resultados, propusemos aos alunos, neste mesmo anúncio, que nos transmitissem seu endereço e-mail no fim do questionário, para que pudéssemos lhes comunicar em retorno seu estilo de aprendizagem. Dois testes eram administrados em seguida para detectar o estilo de aprendizagem privilegiado ou o sentimento de eficácia pessoal declarado pelos sujeitos.

\section{Figura 3}

Esquema 4: as competências digitais

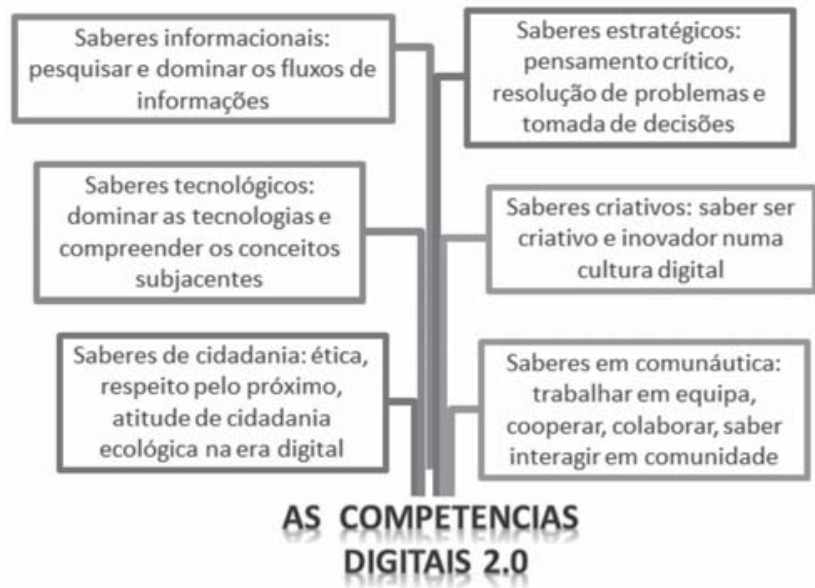

Fonte: Pedagogeeks.

\section{Figura 4}

Esquema 5: as competências digitais

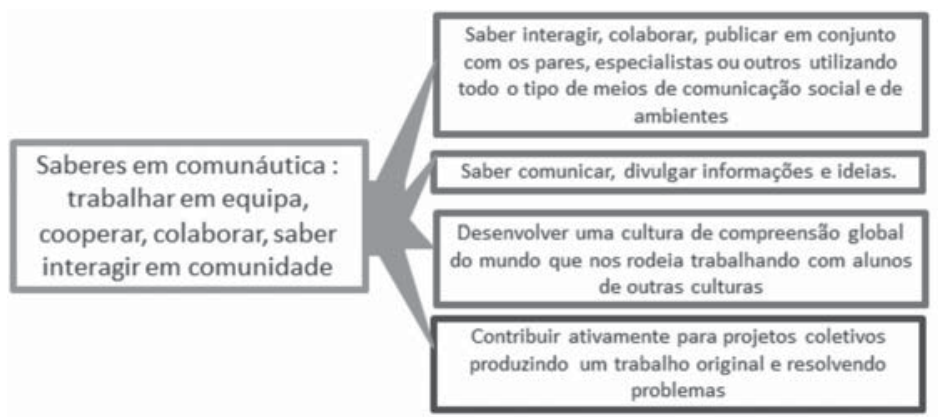

Fonte: Pedagogeeks. 
O questionário estava estruturado em seis grandes partes distintas: TIC e formação; Teste sobre os estilos de aprendizagem; Opiniões sobre as práticas coletivas na formação; Representações sociais sobre tecnologias educativas e educação; Medida do sentimento pessoal de eficácia no trabalho em grupo e, enfim, sobre o domínio das competências digitais e a capacidade de aprender online.

Hipótese geral: Os alunos favoráveis à aprendizagem online e que adotam uma atitude de participação ativa desenvolvem práticas de aprendizagem específicas. Estas práticas estão geralmente centradas em torno do coletivo. Podemos operacionalizá-las sob a forma das seguintes hipóteses operacionais:

SH1: O fato de ser favorável às práticas coletivas de formação é correlato ao sentimento de eficácia em matéria de competências digitais.

SH2: A opinião sobre as práticas coletivas digitais na formação é correlata às variáveis de identificação.

SH3: A adesão e os usos em matéria de práticas comunáuticas de formação são funções do estilo de aprendizagem pessoal.

Público: Nossa amostra se compunha de 176 pessoas inscritas em cursos universitários ou de formação contínua. Colocamos o questionário eletrônico em cinco sites de formação online. Houve em cada caso uma nota enviada aos estudantes. Estimamos que a população envolvida seja de, aproximadamente, 600 a 900 pessoas, o que dá uma porcentagem de respostas de $29,3 \%$ a $19,5 \%$.

A grande maioria (69,9\%) das pessoas que responderam são mulheres, o que se explica principalmente pelas formações seguidas. A taxa média de repartição por gênero para estes estabelecimentos é de $70 \%$. A repartição por gênero é, portanto, representativa da população inicial. A repartição segundo os estabelecimentos é a seguinte: 16,5\% estão inscritos no Cned, 32,4\% no SED Mirail e 5,1\% no IED Paris 8, organismos de formação que contam em média com mais de $70 \%$ de mulheres entre seus inscritos. A ESC Toulouse representa 13,1\% dos que responderam e a Université Limoges, $32,4 \%$.

No que se refere à idade, $36,4 \%$ das pessoas que responderam têm entre 18 e 25 anos; 31,3\% têm entre 30 e 45 anos. Os com mais de 45 anos representam 8,5\% dos inquiridos.

Por outro lado, o grupo dos que responderam parece se dividir em duas partes quase equivalentes: $52,3 \%$ são estudantes e $47,1 \%$ estão em formação contínua, à procura de emprego ou em licença individual de formação.

Quanto a suas práticas digitais pessoais, parece que a maioria utiliza a internet muito regularmente e não apenas para as funcionalidades de base. De fato, 
um bom número deles tem um comportamento ativo em relação à rede, mesmo se, a priori, muitos concordam em dizer que sua atitude no caso é de observação, de pesquisa de informações. Enfim, para nosso estudo, devemos salientar que $88 \%$ das pessoas que responderam afirmam já ter participado de uma aprendizagem online.

Análise: As análises cruzadas entre as variáveis de opiniões sobre as utilizações digitais e os dados sociais mostram que o gênero tinha uma influência efetiva. De fato, quando cruzamos a opinião diante do trabalho de grupo e o gênero, constatamos que, em grande maioria, as mulheres são mais adeptas do trabalho individual que do coletivo. Efetivamente, à questão "Se seu formador exigisse que seu trabalho em grupo seja realizado online", cerca de $82 \%$ das mulheres responderam que isso seria negativo, em comparação a apenas $60 \%$ dos homens. Nesta mesma perspectiva, à questão "Se você tivesse que seguir uma formação inteiramente online", 72\% das mulheres responderam que isso seria provavelmente negativo, contra $52 \%$ dos homens. A prática da ferramenta informática na situação de aprendizagem continua a ser um eixo de separação dos gêneros. Isso pode se explicar por três variáveis importantes, que nos levam a considerar os resultados precedentes como não estabilizados.

De fato, se examinarmos o quadro seguinte, que sintetiza os efeitos do gênero, constataremos que a relação com o computador e com as utilizações digitais ainda é estruturada pelo gênero.

\section{Quadro 1}

\begin{tabular}{|l|c|c|}
\hline & Homem & Mulher \\
\hline Possuo um computador pessoal há mais de 10 anos. & $28 \%$ & $17 \%$ \\
\hline Acha que está muito preso(a) à internet. & $2 \%$ & $8 \%$ \\
\hline Acha que o computador é fatigante e insecurizante. & $2 \%$ & $10 \%$ \\
\hline Você utiliza o telefone celular com muita frequência? & $24 \%$ & $36 \%$ \\
\hline Você utiliza o telefone por motivos práticos. & $71 \%$ & $54 \%$ \\
\hline Eu me sinto eficaz diante do computador. & $63 \%$ & $44 \%$ \\
\hline Utilizo facilmente o computador para os estudos. & $82 \%$ & $32 \%$ \\
\hline Acho as redes sociais interessantes. & $36 \%$ & $52 \%$ \\
\hline $\begin{array}{l}\text { Utilizo as redes sociais para meu lazer e minhas } \\
\text { amizades. }\end{array}$ & $29 \%$ & $67 \%$ \\
\hline Você participa de fóruns de discussão online. & $29 \%$ & $8 \%$ \\
\hline Você já aprendeu coisas nos fóruns. & $38 \%$ & $12 \%$ \\
\hline Você utiliza o telefone para o lazer e para conversar. & $34 \%$ & $67 \%$ \\
\hline
\end{tabular}

É evidente, portanto, que os homens e as mulheres de nossa pesquisa têm usos diferentes do digital. De fato, trabalhos de pesquisa mais antigos sobre as TICs e o 
gênero já haviam mostrado a fratura existente ao nível das utilizações e do sentimento de eficácia em relação à ferramenta, mas nossa pesquisa nos mostra também que as mulheres têm uma prática do digital bastante centrada sobre o relacional, as redes pessoais, e rejeitam as utilizações pedagógicas. Esta orientação para a não utilização das tecnologias na formação, bem como para práticas mais individuais da aprendizagem, é ilustrada no quadro a seguir.

\section{Quadro 2}

\begin{tabular}{|l|c|c|}
\hline & Homem & Mulher \\
\hline Quando comunicamos com as TICs, é pouco caloroso. & $6 \%$ & $23 \%$ \\
\hline $\begin{array}{l}\text { É mais complicado construir realmente conhecimentos } \\
\text { coletivos online. }\end{array}$ & $6 \%$ & $22 \%$ \\
\hline $\begin{array}{l}\text { Quando realiza um trabalho em grupo (em comparação } \\
\text { com um trabalho individual), você se sente eficaz. }\end{array}$ & $32 \%$ & $16 \%$ \\
\hline Não gosto, em geral, do trabalho em grupo. & $19 \%$ & $36 \%$ \\
\hline $\begin{array}{l}\text { Num trabalho em grupo; há muitas vezes parasitas que } \\
\text { aproveitam para não fazer nada. }\end{array}$ & $6 \%$ & $19 \%$ \\
\hline
\end{tabular}

Os usos digitais dos homens e das mulheres são o reflexo, ao mesmo tempo, de modalidades e de estilos de aprendizagem diferentes e de um relacionamento original estabelecido com a internet e as redes.

\section{Representações, sentimento de pertença e sentimento de eficácia}

Conhecemos o papel desempenhado por estas três variáveis em termos de envolvimento nas práticas e pretendemos avaliar as opiniões dos sujeitos relativamente aos domínios que se seguem.

Representação da aprendizagem - As opiniões recolhidas podem se distribuir em dois grupos: pessoas que possuem uma representação da aprendizagem como uma ação co-construída $(51,2 \%)$ e pessoas que pensam que aprender é um ato pessoal individual $(48,8 \%)$.

Sentimento de pertença - Através das questões em causa, pretendemos medir o sentimento dos estudantes de pertencer a um dispositivo de ensino online e a distância e recolher as respectivas opiniões sobre o referido dispositivo (79,5\% afirmam frequentar este tipo de formação). As trocas com o professor responsável pelo curso têm muita importância no investimento do aluno na respectiva formação; por isso se revelou interessante abordar o assunto. Cerca de $80 \%$ dos alunos afirmam realizar trocas virtuais com o professor e cerca de $21 \%$ não mantêm interações virtuais e pouco ou nenhum contato com o professor. $54,2 \%$ afirmam utilizar o espaço digital de 
trabalho para investir e participar na formação, ao passo que $45,8 \%$ apenas o fazem mediante solicitação do professor. Por outro lado, 80,6\% dos inquiridos afirmam que os espaços digitais de trabalho ou a plataforma correspondem às respectivas expectativas.

\section{Quadro 3}

Distribuição das representações da aprendizagem

\begin{tabular}{|l|c|}
\hline Aprender é compreender. & $71.8 \%$ \\
\hline Aprender é envolver-se, experimentar. & $54.8 \%$ \\
\hline Aprender é construir o próprio saber. & $53.7 \%$ \\
\hline Aprender é trocar, dialogar. & $46.9 \%$ \\
\hline Aprender é receber informações. & $44.6 \%$ \\
\hline Aprender é ouvir, memorizar. & $33.3 \%$ \\
\hline Aprender é trabalhar com os outros. & $28.8 \%$ \\
\hline Aprender é observar e reproduzir. & $26 \%$ \\
\hline Aprender é repetir, exercitar. & $25.4 \%$ \\
\hline Aprender é contradizer, modificar. & $14.7 \%$ \\
\hline
\end{tabular}

Sentimento de eficácia - medimos três níveis de sentimento de eficácia dos sujeitos:

a) O sentimento de eficácia digital (abrangendo o sentimento técnico, relacional e de domínio de utilizações): 49,4\% afirmam ser eficazes, 42,6\% bastante eficazes e $6,3 \%$ pouco eficazes;

b) O sentimento de eficácia num trabalho de grupo (pedimos aos inquiridos que comparassem a respectiva eficácia pessoal relativamente a trabalhos de grupo ou a trabalhos individuais): 52,3\% afirmaram ser mais eficazes em trabalhos de grupo, ao passo que 40,3\% afirmaram ser mais eficazes em trabalhos individuais;

c) O sentimento de eficácia em e-learning (medição da capacidade de aprender online no conjunto destas fórmulas): 56,9\% afirmaram ser sempre eficazes ou com muita frequência, contra $43,1 \%$ que afirmaram ser pouco ou nada eficazes.

A análise destes três níveis de sentimento de eficácia pessoal dos sujeitos demonstra uma forte relação estatística entre estas variáveis e a representação da aprendizagem. 


\section{Quadro 4}

Tabela cruzada das variáveis inerentes à eficácia (valor $\mathrm{p}$ )

\begin{tabular}{|l|c|c|c|c|}
\hline \multicolumn{1}{|c|}{$\begin{array}{c}\text { Tabela de ligações } \\
\text { cruzadas }\end{array}$} & $\begin{array}{c}\text { Eficácia } \\
\text { digital }\end{array}$ & $\begin{array}{c}\text { Eficácia } \\
\text { grupware }\end{array}$ & $\begin{array}{c}\text { Eficácia } \\
\text { e-learning }\end{array}$ & $\begin{array}{c}\text { Representação da } \\
\text { aprendizagem }\end{array}$ \\
\hline Eficácia digital & $<0,0001$ & $<0,0001$ & 0,008 \\
\hline Eficácia grupware & $<0,0001$ & & $<0,0001$ & $<0,0001$ \\
\hline Eficácia e-learning & $<0,0001$ & $<0,0001$ & & $<0,0001$ \\
\hline $\begin{array}{l}\text { Representação da } \\
\text { aprendizagem }\end{array}$ & 0,008 & $<0,0001$ & $<0,0001$ & \\
\hline
\end{tabular}

\section{Implicação, eficácia, satisfação: os três pilares do trabalho coletivo online}

"Implicação, eficácia, satisfação", estas três palavras refletem impressões gerais, sentimentos que procuramos medir para saber se poderiam ser elementos de influência para as práticas coletivas no âmbito da aprendizagem online. Optamos por adotar consistentemente a palavra "implicação" em detrimento de "pertença", uma vez que "implicação" nos parece mais adequada à utilização que lhe pretendemos dar. Devem se considerar vários elementos dos resultados em termos de implicação na formação. Assim, tivemos oportunidade de constatar, à semelhança do que Lewandowski (2003) tinha feito a propósito das comunidades de aprendizagem, que quanto mais os alunos frequentavam cursos online, mais demonstravam propensão para criar grupos de trabalho informais, ou seja, livres de qualquer restrição inerente ao professor. Podemos considerar que os alunos que optam por criar um trabalho suplementar, participando em grupos de trabalho informais, sentem-se particularmente envolvidos na respectiva formação.

Em consequência, facilmente se compreende que a opinião que esses alunos têm relativamente a práticas coletivas em formação seja positiva. Do mesmo modo, solicitando aos inquiridos que avaliassem as respectivas taxas e os motivos de participação no espaço digital de trabalho, pudemos analisar o investimento e confirmar a importância do sentimento de pertença (partimos do princípio de que o sentimento de pertença aumentava com o envolvimento na formação) para a implementação de um trabalho coletivo online. As trocas com o professor - neste caso, as trocas virtuais - possuem um valor considerável para o sucesso de uma aprendizagem online. Por isso, pretendemos conhecer as utilizações de cada um dos inquiridos relativamente ao assunto.

De fato, Tricot e Amadieu (2006) sublinharam o risco de sobrecarga cognitiva na aprendizagem online, não obstante tenham demonstrado também que esta mesma 
profusão de informações constituía uma fonte de aprendizagens implícitas e explícitas, mas que estas estratégias deveriam ser orientadas pelo formador. Assim, quantas mais forem as trocas com o formador e, sobretudo, consideradas suficientes pelo aluno, mais real é a qualidade da formação e da aprendizagem. Constatamos que os alunos satisfeitos com as trocas realizadas com o professor se revelaram, de um modo geral, favoráveis e "à vontade" com o princípio do trabalho coletivo. Esta constatação é idêntica quando se fala de satisfação global relativamente à formação adotada.

A noção de eficácia na formação é amplamente abordada em nosso questionário. Esta escolha não foi um mero acaso, uma vez que tivemos oportunidade de constatar, através da teoria da autoeficácia de Bandura (1976), que a percepção que o aluno tem de si próprio e de suas capacidades contribui para seu modo de raciocinar, para sua motivação e para seu comportamento em formação. Assim, quanto mais o aluno se "sentir capaz", mais longe irá em seu percurso de aprendizagem. Constatamos que a tendência a utilizar a web para se comunicar no âmbito de um trabalho coletivo aumenta com o sentimento de eficácia. Ao que parece, a prática coletiva necessita dispor de um forte sentimento de eficácia técnica e pedagógica. Este fato leva-nos a pensar que esta nova prática pode ser considerada como de risco. O sentimento de eficácia pessoal é um elemento que favorece esta assunção de risco. No entanto, também é necessário pensar que esta prática, quando bem-sucedida, conduz ao aumento do sentimento de eficácia. Com efeito, a situação de confrontação e de troca inerente à prática coletiva de aprendizagem permite promover acordos e consensos, funcionando como indicador da eficácia para o sujeito (processo vicariante). Destacamos numa das questões abertas que os indivíduos que se sentiam eficazes evocavam geralmente um motivo: o fato de eles mesmos poderem gerir a respectiva formação e o tempo de trabalho. Podemos abordar o tema à luz do princípio da participação de Lave e Wenger (1991), que indica que o fato de o aluno participar ativamente na respectiva aprendizagem (nomeadamente num trabalho de grupo) é o motor essencial da construção do saber.

O sentimento de eficácia condicionaria, então, a adesão a qualquer prática de aprendizagem coletiva. De resto, isso é também o que parecem ilustrar os propósitos recorrentes dos inquiridos. Na verdade, quando a questão lhes é colocada abertamente, os inquiridos transmitem majoritariamente a ideia de que a homogeneidade do grupo é uma condição intrínseca para o sucesso da colaboração entre alunos e para a respectiva adesão a esta estratégia de aprendizagem. Na sequência de Harvey (2001), que destacou o fato de as redes de relações cognitivas servirem para a produção de conhecimentos, os inquiridos invocaram a ideia de um enriquecimento mútuo pela complementaridade das pessoas e pela troca associada de saberes.

Por outro lado, verificamos, através de determinadas respostas, que as pessoas que se sentem ineficazes na respectiva formação evocam motivos técnicos e organizacionais e, de modo geral, consideram o trabalho coletivo como suplementar, que 
gera um excesso de trabalho. Esta problemática se junta à sobrecarga cognitiva, mas também à enunciada por Rouet (2000). Com efeito, este autor relembra que a aprendizagem através da navegação por hipertexto solicita a aquisição de determinados processos mentais que advêm de um novo conhecimento ao nível da linguagem. A partir do momento em que o aluno domina os processos mentais, tem a possibilidade de se comunicar eficientemente com as outras pessoas. Para além disso, o domínio ou a sua inexistência relativamente às ferramentas também se relaciona com o sentimento de segurança do aluno, determinando o início das trocas sem correr riscos. Confirmamos ainda o papel do sentimento de domínio como vetor de inovação nas utilizações digitais (Alava, 2000). Os sentimentos de eficácia pessoal atuam como elemento positivo ou negativo.

\section{Figura 5}

Esquema 7: variáveis em jogo no âmbito das práticas em comunáutica

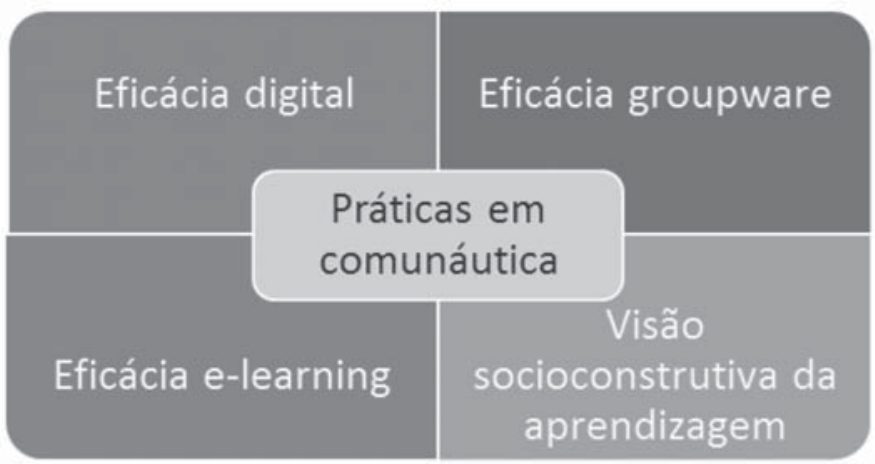

\section{Figura 6}

Esquema 8: variáveis em jogo no âmbito das práticas individuais

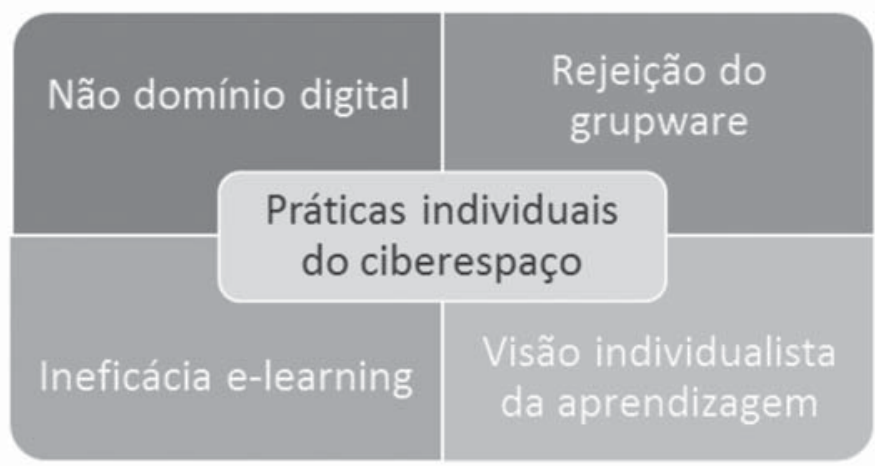




\section{As práticas digitais pessoais como ponto de partida de uma inteligên- cia conectiva}

Verificamos, através de uma tabela de frequências das respostas, que a maior parte dos inquiridos mantinha quotidianamente uma atividade recorrente na internet e que as respectivas representações da rede e das TICs eram, de um modo geral, positivas. Cruzando estas informações com a opinião emitida sobre as práticas coletivas de aprendizagem, obtivemos resultados bastante significativos. Assim, tivemos a possibilidade de formular a ideia de que o fato de se manter quotidianamente uma atividade recorrente na internet poderia influenciar a adesão a práticas coletivas de formação, particularmente no que diz respeito a pessoas com uma postura bastante participativa em fóruns ou comunidades virtuais. Portanto, tal como considerava McLuhan (1968), estaríamos aqui a experimentar o fenômeno de retribalização favorecida pelo meio de comunicação social "cool" que a internet representa: um meio de comunicação social que desenvolveria um pensamento comunitário e a interdependência entre as pessoas. Levy (1997) afirmava também que o fato de compartilhar informações e saberes através da rede contribuía para o aumento da inteligência conectiva. Pode-se supor que isso também favoreceria a prática do trabalho colaborativo na aprendizagem.

\section{Figura 7}

Esquema 9: variáveis ativas para reforçar as competências em comunáutica

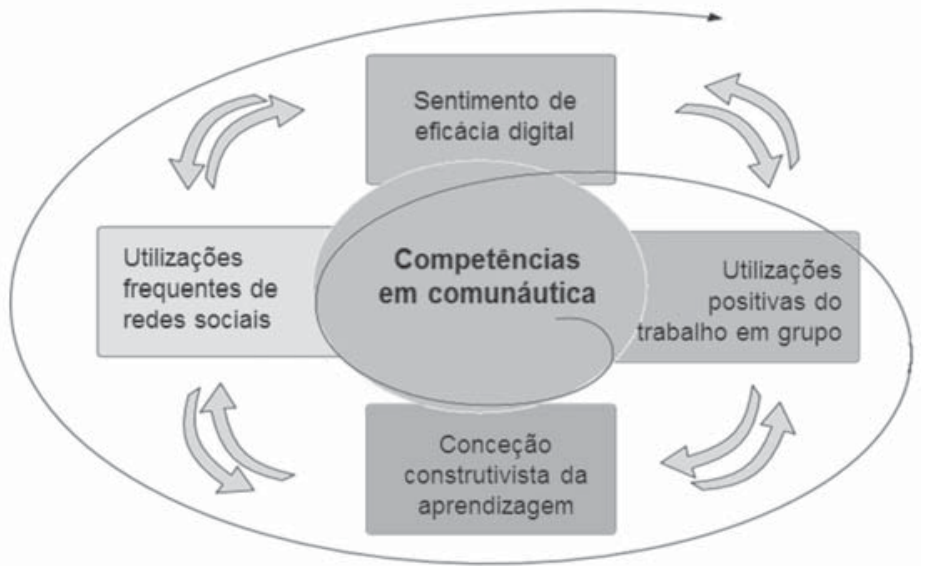

O segundo elemento importante a sublinhar em nossa análise é aquilo a que Bandura chamou antecipação cognitiva. De fato, constata-se que quem passou pela experiência da aprendizagem formal ou não através da internet tem, geralmente, 
uma opinião positiva relativamente a práticas colaborativas de aprendizagem online. Assim, o fato de ter superado online uma situação semelhante à do trabalho coletivo permitiria ao aluno apreender essa situação mais facilmente e, por isso, revelar-se favorável.

\section{Práticas colaborativas e estilos de aprendizagem: uma ligação a confirmar}

Se existisse uma hipótese cujo resultado pudéssemos prever, não seria este com certeza. De fato, uma vez que o estudo de Isalem (1996) evoca o estilo de aprendizagem como a forma preferencial de abordar um problema, parece lógico à primeira vista que o estilo de aprendizagem tenha uma influência sobre a opinião do aluno relativamente a práticas coletivas de aprendizagem. Determinados alunos, em função da forma de aprender e das estratégias implementadas (Hrimech, 2006), estarão mais ou menos à vontade numa ação coletiva. No entanto, esta ligação não foi verificada através dos resultados do nosso inquérito. Não se revela de forma evidente que os estilos de aprendizagem tenham influência sobre as opiniões em termos de práticas coletivas.

Podemos evocar dois eventuais motivos para este resultado. Na verdade, a tendência dos alunos que fazem parte de nossa amostra a serem majoritariamente intuitivos não permite estabelecer uma correlação. Do mesmo modo, podemos pensar que é a experiência, a prática em formação aberta e a distância que transformam o estilo de aprendizagem de cada um. Deste modo, assiste-se a uma uniformização das práticas.

Contudo, esta ligação entre as práticas em comunáutica e os estilos dos alunos parece estar correlacionada com dois estilos (Isalem, op. cit.) - os intuitivos e os reflexivos -, quando realizamos uma análise por correspondência múltipla (ACM). Esta permitiu valorizar três eixos de distribuição de variáveis que estruturam o conjunto de posições e opiniões dos sujeitos relativamente às práticas coletivas na internet e em termos de formação aberta e a distância.

\section{Eixo F1: Sentimento pessoal de eficácia e opinião positiva para o trabalho de grupo e os fóruns}

A ACM destaca um eixo de distribuição de variáveis e de modalidades relativamente a três domínios:

a) por um lado, os sentimentos pessoais de eficácia relativamente à capacidade de aprendizagem e à frequência dos cursos; 
b) participação pessoal dos sujeitos nos fóruns, utilização frequente de fóruns e de grupos de estudo;

c) opinião favorável ou desfavorável relativamente à incorporação do trabalho em grupo na aprendizagem.

\section{Figura 8}

Esquema 10: eixo F1 da ACM

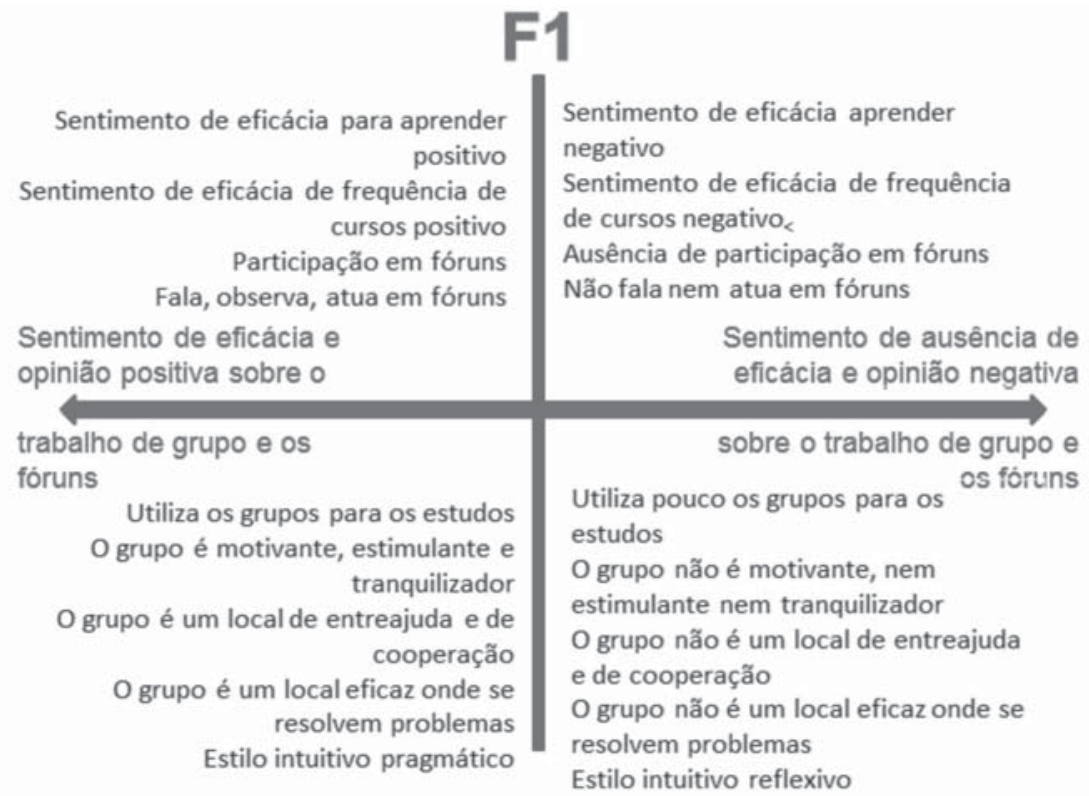

Confirmamos nossas análises anteriores e vemos que as práticas comunáuticas dependem, neste eixo, do sentimento positivo relativamente às capacidades do sujeito, de uma prática confirmada em termos de fóruns e de trocas na internet e de sentimentos positivos relativamente ao trabalho de grupo em formação.

\section{Eixo F2: experiência e domínio das ferramentas e das utilizações digitais}

Este eixo separa os sujeitos relativamente a dois domínios:
A) o domínio técnico do computador, da internet e de técnicas digitais;
B) a experiência positiva ou negativa relativamente à formação aberta e a distância e ao trabalho de grupo online.




\section{Figura 9}

Esquema 11: eixo F2 da ACM

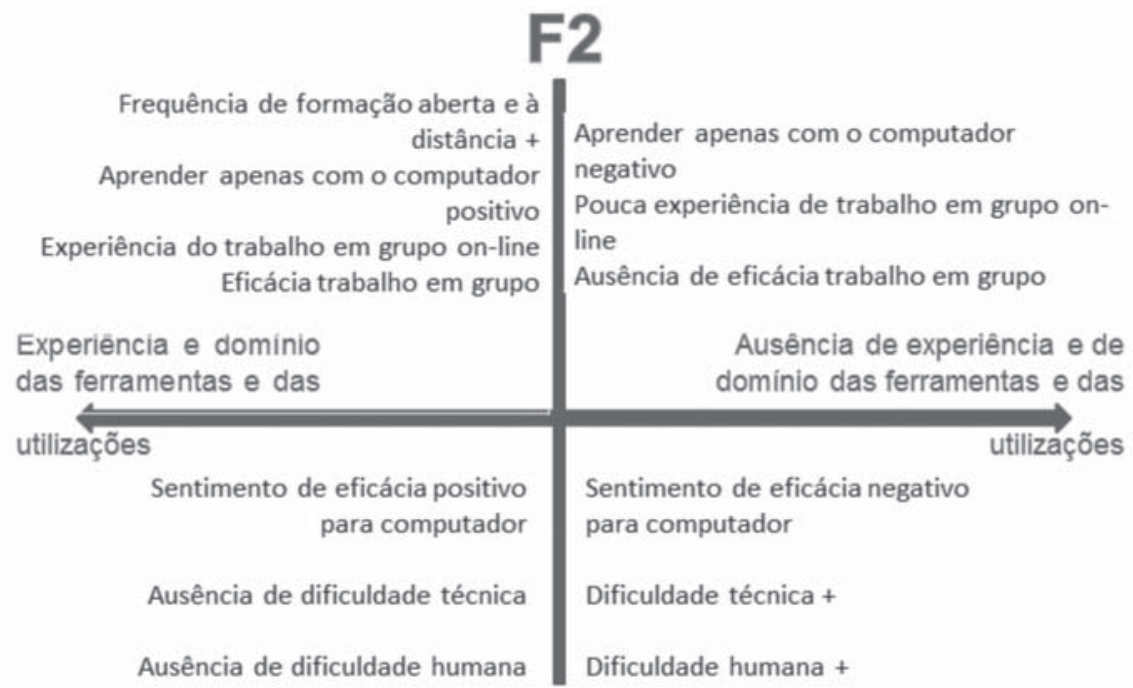

Quanto mais especializados são os sujeitos do ponto de vista digital, mais experimentam as trocas online. Quanto mais experiência concreta possuem relativamente ao ensino online, mais os sujeitos desenvolvem práticas coletivas de formação e de aprendizagem.

\section{Eixo F3: interação e gosto pela troca}

As práticas coletivas em formação online também estão correlacionadas com a experiência positiva de interação virtual e de trocas interpessoais digitais. Estas trocas também estão correlacionadas com o sentimento mais ou menos positivo que o sujeito experimenta relativamente às respectivas capacidades para aprender e frequentar cursos online. Esta relação pessoal feita de utilizações e de opiniões afeta a emergência das práticas coletivas. 


\section{Figura 10}

Esquema 12: eixo F3 da ACM

\begin{tabular}{|c|c|}
\hline \multicolumn{2}{|c|}{ 도 } \\
\hline $\begin{array}{r}\text { Género masculino } \\
\text { Sentimento de eficácia de frequência de } \\
\text { cursos positivo } \\
\text { Sep aprender positivo }\end{array}$ & $\begin{array}{l}\text { Género feminino } \\
\text { Sentimento de eficácia de frequência de } \\
\text { cursos negativo } \\
\text { Sentimento de eficácia aprender negativo }\end{array}$ \\
\hline $\begin{array}{l}\text { Sentimento de eficácia e } \\
\text { apreciador de trocas e de }\end{array}$ & $\begin{array}{l}\text { Sentimento de ausência de } \\
\text { eficácia e não apreciador de }\end{array}$ \\
\hline interação & trocas \\
\hline $\begin{array}{r}\text { Aprecia a interação na Internet } \\
\text { Passa tempo na internet em websites de } \\
\text { trocas } \\
\text { O grupo é um local eficaz onde se } \\
\text { resolvem problemas } \\
\text { Estilo intuitivo }\end{array}$ & $\begin{array}{l}\text { Não privilegia os websites de trocas na } \\
\text { Internet } \\
\text { Estilo reflexivo } \\
\text { Não procura a interação na Internet } \\
\text { O grupo não é um local eficaz onde se } \\
\text { resolvem problemas }\end{array}$ \\
\hline
\end{tabular}

Em conclusão, pretendemos agrupar apenas as variáveis e as modalidades correlacionadas com os eixos (0,05 KHI2). Assistimos ao surgimento de quatro grupos que se caracterizam relativamente às práticas comunáuticas e que fazem surgir uma orientação relacionada com os estilos de aprendizagem.

\section{Figura 11}

Esquema 13: Característica das classes de práticas em comunáutica

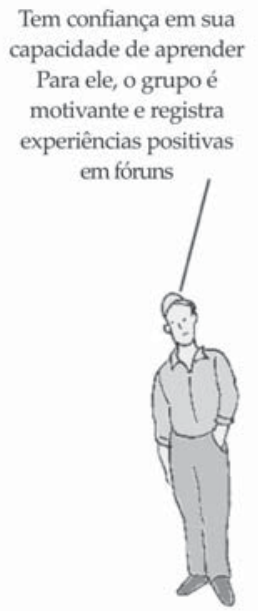

Estilo intuitivo

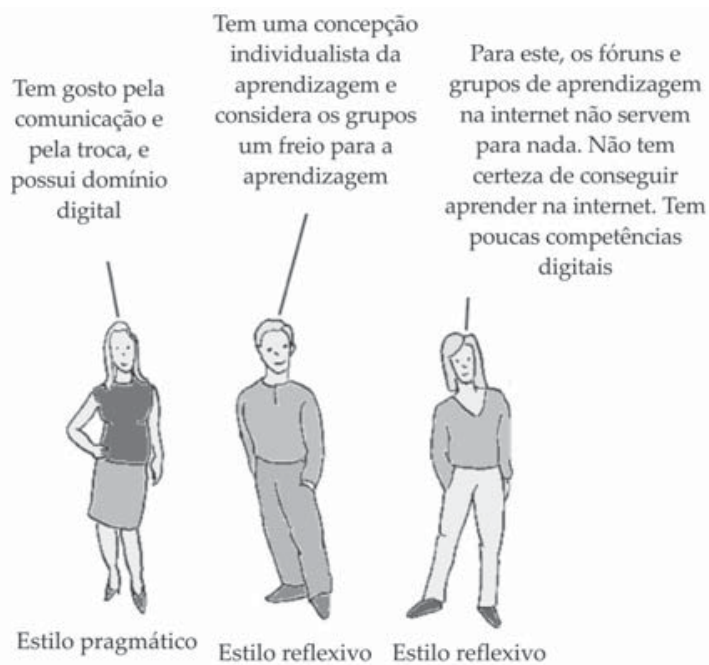


Em conclusão, como Lewandowski (2003) já o havia mostrado a propósito das comunidades de aprendizagem, quanto mais os alunos já tivessem seguido cursos online, mais estes mostravam uma propensão a criar grupos de trabalho informais, isto é, livres de qualquer imposição por parte do formador. Podemos considerar que os alunos que tomam a iniciativa de criar para si mesmos um trabalho suplementar, participando de grupos de trabalho informais, se sentem particularmente implicados na própria formação. A noção de eficácia na formação é amplamente abordada em nosso questionário. Assim, quanto mais o aluno se "sentir capaz", mais longe ele irá em sua aprendizagem. Podemos aproximar esta noção do princípio de participação de Lave e Wenger (1991), que indicava que o fato, para o aluno, de participar ativamente da aprendizagem (principalmente num trabalho de grupo) era o motor essencial da construção do saber.

O sentimento de eficácia condicionaria, portanto, a adesão a qualquer prática de aprendizagem coletiva. Em todo caso, é o que parecem também ilustrar as declarações recorrentes dos inquiridos. De fato, quando a questão lhes é colocada de maneira aberta, eles emitem na maioria a ideia de que a homogeneidade do grupo é uma condição intrínseca para o sucesso da colaboração entre os alunos e, portanto, para sua adesão a esta estratégia de aprendizagem. Como Harvey (2001), que colocou em evidência o fato de que as redes de relações cognitivas serviam à produção de conhecimentos, os inquiridos evocam a ideia de um enriquecimento mútuo pela complementaridade das pessoas e, portanto, por uma troca de saberes.

\section{Conclusão}

Acabamos de apresentar um inquérito cujo objetivo era descrever as práticas coletivas na formação online e compreender quais eram os vetores da adesão e da implementação dessas práticas. Desejávamos nos apoiar nas teorias da aprendizagem social, assim como na psicologia cognitiva. A metodologia que utilizamos se apoiava num questionário de pesquisa online. Após a análise e interpretação de nossos resultados, pudemos validar a maior parte de nossas hipóteses iniciais e concluir que a aprendizagem online provoca, na maioria das vezes, uma modificação dos comportamentos de aprendizagem. Por modificação entendemos o termo de "adaptação", para alguns, e de criação, para outros. Em função do nível de conhecimentos e de prática da internet, cada aluno constrói suas estratégias de aprendizagem. As possibilidades oferecidas pela rede, em matéria de troca de informações, levam a uma passagem progressiva, segundo as formações, a práticas de aprendizagem geralmente coletivas. Assim, muitas vezes, é o organismo de formação e seu corpo docente que são o motor destas práticas, mas os dados que obtivemos nos permitem também dizer que cada vez mais alunos sentem espontaneamente a necessidade de 
trabalhar em grupo, e as comunidades virtuais informais são um exemplo disso. Se os estilos de aprendizagem não são fatores que influenciam a adesão às práticas coletivas de aprendizagem, pode-se legitimamente pensar, em compensação, que a experiência e a cultura digital ocupam aí um lugar essencial.

Existem ainda disparidades importantes de utilização das TICs que dependem da idade dos alunos e de seu ambiente de vida (evocamos aqui, particularmente, os alunos estrangeiros cujas conexões à rede são, às vezes, ainda muito precárias). Se podemos pensar que o fosso digital e cultural, devido em parte à coabitação entre a geração internet e aquela que a viu nascer, tenderá a se reduzir consideravelmente nos próximos anos, é preciso esperar que o mesmo será válido para os países onde o acesso à rede é atualmente um luxo indiscutível. Nesta lógica, as opiniões em relação às práticas coletivas de aprendizagem deveriam evoluir positivamente. Com efeito, como imaginar que a nova geração, habituada à comunicação e às interações permanentes, através principalmente da Web 2.0, poderia se mostrar reticente diante dessas práticas? Contudo, podemos igualmente nos interrogar sobre como o ensino poderia, no futuro, ignorar esses novos modos de comunicação e de trocas de saberes.

\section{Referências}

ALAVA S. Cyberspace et pratiques de formation: des mirages aux usages des enseignants. In: ALAVA, S. Cyberespace et autoformation: vers une mutation des dispositifs de formation. Bruxelles: De Boeck, 2000. p. 45-64.

AMADIEU, F.; TRICOT, A. Utilisation d'un hypermédia et apprentissage: deux activités concurrentes ou complémentaires? Psychologie Française, v. 51, n. 1, p. 5-23, 2006.

BANDURA, A. L'apprentissage social. Bruxelles: P. Mardaga, 1976.

BATESON, G.; RUESCH, J. Communication: the social matrix of psychiatry. New York: Norton, 1951.

BILLINGS, D.M.; COBB, K.L. Effects of learning style preferences. Journal of Computer-Based Instruction, v. 19, n. 1, p. 12-161, 992.

BLANDIN, B. Environnements d'apprentissage. Paris: L'Harmattan, 2007.

BRUNER, J. Car la culture donne forme à l'esprit: de la révolution cognitive à la psychologie culturelle. Paris: Eshel, 1990.

CARRÉ, P. L'Apprenance, vers un nouveau rapport au savoir. Paris: Dunod, 2005. 
CASTEIGNAU, G.; GONON, I. Pratique du travail collaboratif en communautés virtuelles d'apprentissage: fractures dans la société de la connaissance. Hermes, Paris, n. 45, p. 109-115, 2006.

CHARLIER, B.;DAELE, A. Pourquoi les communautés d'enseignants aujourd'hui? In: DAELE, A.; CHARLIER, B. (Ed.). Comprendre les communautés virtuelles d'enseignants: pratiques et recherches. Paris: L'Harmattan, 2006. p. 83-103.

CONEIN, B. Communautés épistémiques et réseaux cognitifs: coopération et cognition distribuée. Revue d'Économie Politique, Paris, n. 113, p. 85, 2004.

CONKLIN, J. Hypertext: an introduction and survey. IEEE Computer, v. 20, n. 9, p. 17-41, Sept. 1987.

DE KERCKHOVE, D.; SCHEFFEL-DUNAND, D. Les réseaux du savoir: un nouvel espace sémiotique à explorer. Comunicação apresentada na Feira de Estudos Franceses em 2000 e no Colóquio Internacional, subordinada ao tema: "Les études françaises valorisées par les nouvelles technologies d'information et de communication". Toronto, maio 2002. Disponível em: <http://www.etudes-francaises.net/colloque/ddkdsd.htm\#tit3>

DORÉ, S.; BASQUE, J. Le concept d'environnement d'apprentissage informatisé. Revue de l'Éducation à Distance, v. 13, n. 1, p. 40-56, 1998.

FAERBER, R. Accompagner les apprentissages à distance et collaborer en petits groupes. 2003. Disponível em: <http://faerber.u-strasbg.fr/publi/aecse_faerber.pdf> Acesso em: 12 jul. 2010.

FERONE, G. Interactions électroniques et formation des maîtres. Trabalho apresentado no Colloque des Directeurs d'IUFM, Paris, 9 e 10 décembre 2008.

GARDNER, H. Histoire de la révolution cognitive: la nouvelle science de l'esprit. Paris: Payot, 1993.

GARDNER, H. Les formes de l'intelligence. Paris: Odile Jacob, 1997.

GHARSALLAH, M. Internet et l'intelligence collective. Tence: Universidade de Tence, 19 maio 2007.

HARVEY, P.L. Cyberespace et communautique. Laval: Université Laval, 1995.

HARVEY, P.L.; LEMIRE, G. La nouvelle éducation: NTIC, transdisciplinarité et communautique. Paris: L'Harmattan, 2001.

HELLOUIN, V. Apprentissage collaboratif en ligne: la valeur ajoutée des pédagogies actives. In: HELLOUIN, V. (Dir.). E-formation: phase opérationnelle. Paris: Centre Infflo, 2003. p. 228-234. 
HRIMECH, M. Autoformation et développement de compétences au travail: le rôle des stratégies d'apprentissage. In: CONGRÈS DE L'ASSOCIATION CANADIENNE POUR L'ETUDE DE L'ÉDUCATION DES ADULTES., 2003, Toronto. Actes $d u$... Toronto, 2006. Disponível em: <http://www.oise.utoronto.ca/CASAE/ cnf2003/2003_papers/mohamed-hrimechCAS03.pdf>. Acesso em: 10 maio 2010.

HRIMECH, M. Stratégies d'autoformation pour l'acquisition de compétences essentielles dans le milieu du travail. Disponível em: <http://www.competencesessentielles.uqam. ca/fr/pdf/Hrimech.pdf $>$. Acesso em: 10 maio 2010.

ISALEM. Styles d'enseignement, styles d'apprentissage et pédagogie différenciée en sciences. Liège: Laboratoire d'Enseignement Multimédia (LEM), Université de Liège, 1996

KEEBLE L.; LOADER B.L. Community informatics. London: Routledge, 2002.

LAVE J.; WENGER E. Situated learning. Legitimate peripheral participation. Cambridge: University of Cambridge Press, 1991.

LEGROS, D. La construction des connaissances par le multimédia: apprendre avec le multimédia, où en est-on? Paris: Retz, 1997.

LEGROS, D.; CRINON, J. Psychologie des apprentissages multimédias. Paris: Armand Collin, 2002.

LEVY, P. Cyberculture. Paris: Odile Jacob, 1997.

LEVY, P. L'intelligence collective. Paris: La Découverte, 1994.

LEWANDOWSKI, J.C. Les nouvelles façons de former - le e-learning, enjeux et outils. Paris: Editions d'Organisation, 2003.

LOISIER, J.; MARCHAND, L. Pratiques d'apprentissage en ligne. Montreal: Chenelière Education, 2005.

MCLUHAN, M. Pour comprendre les médias. Paris: Seuil, 1968.

MEHRA, B. Service learning in library and information science education: connecting research and practice to community. Interactions: Ucla Journal of Information and Education Studies, v. 1, 2004.

MORINO, M. Assessment and evolution of community networking. Paper presented at the ties that Bind Conference on Bulding Community Netwoks. Cupertino, CA, 1994. Disponível em: <http://www.morino.org/publications/assessment.html>

PINTE, J.P. Les réseaux sociaux sont des outils d'apprentissage en devenir. Interview, "blog de la veille". Disponível em: <http://www.demainlaveille.fr/2009/04/24/les-reseauxsociaux-sont-des-outils-dapprentissage-en-devenir> Acesso em: 12 jul. 2010. 
RHEINGOLD H. Les communautés virtuelles. Paris: Addison-Wesley, 1993.

ROUET, J.-F. Pourquoi "bien lire" ne suffit pas: l'acquisition des stratégies de compréhension au collège et au lycée. In: GAONAC'H, D.; GOLDER C. (Dir.). Manuel de psychologie. Paris: Hachette Education, 2001. p. 132-143.

SARR, M. Du cyberespace à New York: la communautique et l'intelligence collective. 2002. Thèse (Doctorat, PhD) - Faculté des Sciences Sociales, Université de Laval, Quebec.

SCHULER, D. New community networks: wired for change. New York: ACM Press, 1996. SLEVIN, J. The internet and society. Cambridge, UK: Polity Press, 2000.

STAHL, G. Yes we can! International Journal of Computer-Supported Collaborative Learning, v. 4, n. 1, p. 1-4, 2009.

WELLMAN,B. Physical place and cyberplace, the rise of networked individualism. In: KEEBLE L.; LOADER B.L. Community informatics. London: Routledge, 1999. p. 18-52.

Recebido em 15 de agosto de 2012.

Aprovado em 17 de outubro de 2012. 